\title{
Association of genetic variants with hypertension in a longitudinal population-based genetic epidemiological study
}

\author{
YOSHIJI YAMADA ${ }^{1,2}$, KOTA MATSUI $^{2,3}$, ICHIRO TAKEUCHI $^{2,3}$, MITSUTOSHI OGURI $^{4}$ and TETSUO FUJIMAKI ${ }^{5}$ \\ ${ }^{1}$ Department of Human Functional Genomics, Life Science Research Center, Mie University, Tsu, Mie 514-8507; \\ ${ }^{2}$ Core Research for Evolutionary Science and Technology (CREST), Japan Science and Technology Agency, \\ Tokyo 102-0076; ${ }^{3}$ Department of Scientific and Engineering Simulation, Graduate School of Engineering, \\ Nagoya Institute of Technology, Nagoya 466-8555; ${ }^{4}$ Department of Cardiology, Japanese Red Cross Nagoya First Hospital, \\ Nagoya 453-8511; ${ }^{5}$ Department of Cardiovascular Medicine, Inabe General Hospital, Inabe, Mie 511-0428, Japan
}

Received December 8, 2014; Accepted March 3, 2015

DOI: 10.3892/ijmm.2015.2151

\begin{abstract}
We previously identified 9 genes and chromosomal region $3 \mathrm{q} 28$ as susceptibility loci for Japanese patients with myocardial infarction, ischemic stroke, or chronic kidney disease by genome-wide or candidate gene association studies. In the present study, we investigated the possible association of 13 single nucleotide polymorphisms (SNPs) at these 10 loci with the prevalence of hypertension or their association with blood pressure (BP) in community-dwelling individuals in Japan. The study subjects comprised 6,027 individuals (2,250 subjects with essential hypertension, 3,777 controls) who were recruited into the Inabe Health and Longevity Study, a longitudinal genetic epidemiological study on atherosclerotic, cardiovascular and metabolic diseases. The subjects were recruited from individuals who visited the Health Care Center of Inabe General Hospital for an annual health checkup, and they are followed up each year (mean follow-up period, 5 years). Longitudinal analysis with a generalized estimating equation and with adjustment for age, gender, body mass index and smoking status revealed that rs 2116519 of family with sequence similarity 78, member B (FAM78B; $\mathrm{P}=0.0266)$, rs6929846 of butyrophilin, subfamily 2, member A1 (BTN2Al; $\mathrm{P}=0.0013)$, rs146021107 of pancreatic and duodenal homeobox 1 (PDXI; $\mathrm{P}=0.0031)$ and rs1671021 of lethal giant larvae homolog 2 (Drosophila) $(L L G L 2 ; \mathrm{P}=0.0372)$ were significantly $(\mathrm{P}<0.05)$ associated with the prevalence of hypertension. Longitudinal analysis with a generalized linear mixed-effect model and with adjustment for age, gender, body mass index and smoking status among individuals not taking anti-hypertensive medication revealed that rs6929846 of BTN2Al was significantly associ-
\end{abstract}

Correspondence to: Professor Yoshiji Yamada, Department of Human Functional Genomics, Life Science Research Center, Mie University, 1577 Kurima-machiya, Tsu, Mie 514-8507, Japan

E-mail: yamada@gene.mie-u.ac.jp

Key words: hypertension, genetics, polymorphism, genetic epidemiology, longitudinal study ated with systolic $(\mathrm{P}=0.0017)$, diastolic $(\mathrm{P}=0.0008)$ and mean $(\mathrm{P}=0.0005) \mathrm{BP}$, and that $\mathrm{rs} 2116519$ of $F A M 78 B$, rs146021107 of $P D X 1$ and rs1671021 of $L L G L 2$ were significantly associated with diastolic $(\mathrm{P}=0.0495)$, systolic $(\mathrm{P}=0.0132)$, and both diastolic $(\mathrm{P}=0.0468)$ and mean $(0.0471) \mathrm{BP}$, respectively. $B T N 2 A 1$ may thus be a susceptibility gene for hypertension.

\section{Introduction}

Hypertension is a complex multifactorial disorder that is thought to result from an interaction between an individual's genetic background and various lifestyle and environmental factors (1). The genetic influence on blood pressure (BP) variability has been estimated at $30-60 \%$ for a given individual (2), and the genetic heritability of hypertension estimated at $30 \%$ (3). Given that hypertension is a major risk factor for coronary artery disease, ischemic and hemorrhagic stroke, as well as chronic kidney disease (4-6), the personalized prevention of hypertension is an important public health goal.

Genome-wide association studies have identified various loci and genes associated with BP or to a predisposition to hypertension in Caucasian populations (7-11) or African Americans (12). Although the genes for adducin 2 (13) and ATPase, $\mathrm{Ca}^{2+}$ transporting, plasma membrane 1 (14) have been shown to be susceptibility loci for hypertension in Japanese individuals, the genes that confer susceptibility to this condition in Japanese individuals remain to be identified definitively.

We have previously identified 9 genes and chromosomal region 3q28 as susceptibility loci for myocardial infarction, ischemic stroke, or chronic kidney disease in Japanese individuals by genome-wide (15-17) or candidate gene (18-20) association studies. Given that hypertension is an important risk factor for these conditions (4-6), we hypothesized that certain single nucleotide polymorphisms (SNPs) at these 10 loci may contribute to their genetic susceptibility by affecting the susceptibility to hypertension. Therefore, the purpose of the present study was to examine the possible association of 13 SNPs at these 10 loci with the prevalence of essential hypertension or their association with BP in community-dwelling Japanese individuals. 
Table I. The 13 SNPs examined in the present study.

\begin{tabular}{|c|c|c|c|c|}
\hline $\begin{array}{l}\text { Chromosomal } \\
\text { locus }\end{array}$ & Gene & dbSNP (NCBI) & Nucleotide substitution & $\begin{array}{l}\text { Minor } \\
\text { allele }^{\mathrm{a}}\end{array}$ \\
\hline $1 \mathrm{q} 24.1$ & $F A M 78 B$ & rs2116519 & $\mathrm{C} \rightarrow \mathrm{T}$ & $\mathrm{C}$ \\
\hline $3 q 28$ & Non-gene region & rs9846911 & $A \rightarrow G$ & G \\
\hline $4 q 25$ & $A L P K 1$ & rs2074379 & $\mathrm{G} \rightarrow \mathrm{A}($ Met732Ile $)$ & G \\
\hline $4 q 25$ & $A L P K 1$ & rs2074380 & $\mathrm{G} \rightarrow \mathrm{A}($ Gly870Ser $)$ & A \\
\hline $4 q 25$ & $A L P K 1$ & rs2074381 & $A \rightarrow G($ Asn916Asp) & G \\
\hline $4 q 25$ & $A L P K 1$ & rs2074388 & G $\rightarrow$ A (Gly565Asp) & G \\
\hline $6 \mathrm{p} 22.1$ & $B T N 2 A 1$ & rs6929846 & $\mathrm{T} \rightarrow \mathrm{C}$ & $\mathrm{T}$ \\
\hline $6 q 27$ & $T H B S 2$ & rs 8089 & $\mathrm{~T} \rightarrow \mathrm{G}$ & G \\
\hline $13 q 12.1$ & $P D X 1$ & rs 146021107 & $\mathrm{G} \rightarrow-($ deletion $)$ & - \\
\hline $13 q 34$ & $F 7$ & rs6046 & $\mathrm{G} \rightarrow \mathrm{A}(\operatorname{Arg} 353 \mathrm{Gln})$ & A \\
\hline $17 q 25.1$ & $L L G L 2$ & rs1671021 & $\mathrm{G} \rightarrow \mathrm{A}($ Leu479Phe $)$ & G \\
\hline $19 \mathrm{p} 13.2$ & $I L F 3$ & rs2569512 & $\mathrm{G} \rightarrow \mathrm{A}$ & A \\
\hline $22 q 13.3$ & CELSR1 & rs6007897 & $\mathrm{C} \rightarrow \mathrm{T}$ (Ala2268Thr) & $\mathrm{C}$ \\
\hline
\end{tabular}

${ }^{a}$ The minor allele in Japanese individuals was determined by the allele frequency of HapMap-JPT in dbSNP. SNPs, single nucleotide polymorphisms.

\section{Materials and methods}

Study population. Study subjects comprised 6,027 communitydwelling individuals $(2,250$ subjects with essential hypertension and 3,777 controls) who were recruited to a population-based cohort study in Inabe City (Inabe Health and Longevity Study), Mie Prefecture, Japan. The Inabe Health and Longevity Study is a longitudinal genetic epidemiological study of atherosclerotic, cardiovascular and metabolic diseases (21-26). The subjects were recruited from individuals who visited the Health Care Center of Inabe General Hospital for an annual health checkup, and they are followed up each year. A total of 6,027 individuals was registered between March 2010 and September 2012, and genomic DNA was extracted from the venous blood cells of these subjects and stored in the genomic DNA bank of the Research Center for Genomic Medicine at Mie University. For all the participants, medical examination data obtained from April 2003 to March 2014 (11 years) were entered into a database. If individuals had a medical checkup 2 or more times per year, data from one time point for each year were entered, so that each subject had one set of health data for each year they had attended the clinic. All participants thus had undergone 1-11 medical examinations, and the average follow-up period was 5 years.

Subjects with hypertension either had a systolic BP of $\geq 140 \mathrm{mmHg}$ or a diastolic BP of $\geq 90 \mathrm{mmHg}$ (or both) or had taken anti-hypertensive medication. The control individuals had a systolic BP of $<140 \mathrm{mmHg}$ and a diastolic $\mathrm{BP}$ of $<90 \mathrm{mmHg}$, as well as no history of hypertension or of taking any anti-hypertensive medication. BP was measured at least twice with the subjects having rested in the sitting position for $>5 \mathrm{~min}$; the measurements were taken by a skilled physician or nurse according to the guidelines of the American Heart Association (27). The study protocol complied with the Declaration of Helsinki and was approved by the Committees on the Ethics of Human Research of Mie University Graduate School of Medicine and Inabe General Hospital. Written informed consent was obtained from all subjects prior to enrollment in the study.

Selection and genotyping of polymorphisms. The 13 SNPs examined in the present study (Table I) were selected from our previous genome-wide (15-17) or candidate gene (18-20) association studies. Wild-type (ancestral) and variant alleles of the SNPs were determined from the dbSNP database (National Center for Biotechnology Information, Bethesda, MD, USA) (http://www.ncbi.nlm.nih.gov/SNP).

Venous blood $(5 \mathrm{ml})$ was collected into tubes containing $50 \mathrm{mmol} / 1$ ethylenediaminetetraacetic acid (disodium salt), and peripheral blood leukocytes were isolated and genomic DNA was extracted from these cells with the use of a DNA extraction kit (SMITEST EX-R\&D; Medical and Biological Laboratories, Nagoya, Japan). The genotypes of the 13 SNPs were determined at G\&G Science Co., Ltd. (Fukushima, Japan) by a method that combines the polymerase chain reaction and sequence-specific oligonucleotide probes with suspension array technology (Luminex, Austin, TX, USA). The primers, probes and other conditions for the genotyping of the SNPs examined in the present study are shown in Table II. Detailed genotyping methodology was as described previously $(15,16,28)$.

Statistical analysis. Quantitative data were compared between the subjects with hypertension and the controls with the unpaired Student's t-test. Categorical data were compared with the $\chi^{2}$ test. We examined the association of the 13 SNPs with the prevalence of hypertension or their association with systolic, diastolic, or mean BP based on a 5-year longitudinal cohort study. Longitudinal changes in the prevalence of hypertension were compared between 2 groups (the dominant or recessive genetic model) with a generalized estimating equation, as previously described (29) and with adjustment for age, gender, body mass index (BMI) and smoking status. Longitudinal changes in systolic, diastolic, or mean BP in all the individuals 


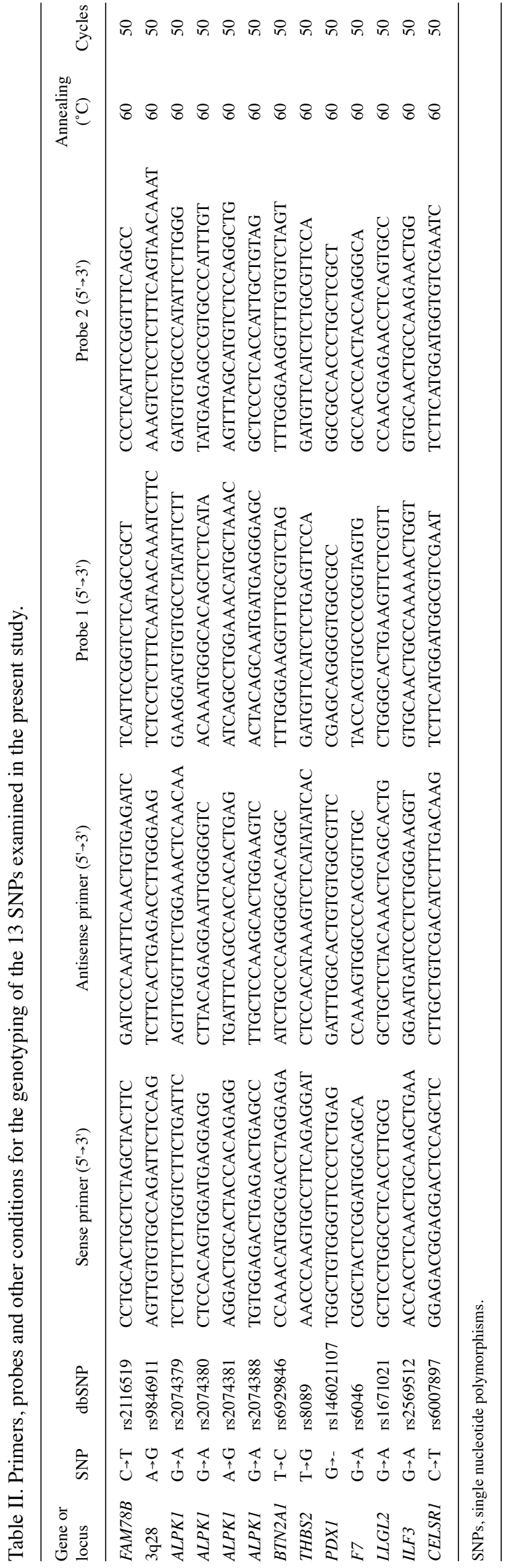

or in the individuals not any taking anti-hypertensive medication were compared between 2 groups (the dominant or recessive model) in a generalized linear mixed-effect model, as previously described (30) with adjustment for age, gender, BMI and smoking status. The dominant or recessive model was defined as $A A$ vs. $A B+B B$ or $A A+A B$ vs. $B B$ ( $A$, major allele; $B$, minor allele), respectively. Age-related changes in the prevalence of hypertension or in systolic or diastolic BP were estimated with quadratic curves controlling for the observation year. A P-value $<0.05$ was considered to indicate a statistically significant difference. Statistical analysis was performed using R software version 3-0-2 (the R Project for Statistical Computing) and JMP Genomics version 6.0 (SAS Institute, Cary, NC, USA).

\section{Results}

Characteristics of the 6,027 study subjects (3,352 males, 2,675 females) with regard to all measurements in a 5-year follow-up are shown in Table III. Characteristics of the subjects with hypertension and the controls according to crosssectional analysis in March 2014 are shown in Table IV. Age, the frequency of the male gender, BMI and the prevalence of smoking were greater in the subjects with hypertension than in the controls.

The association of the 13 SNPs with the prevalence of hypertension was analyzed with a generalized estimating equation and with adjustment for age, gender, BMI and smoking status (Table V). The rs2116519 (C $\rightarrow \mathrm{T})$ SNP of the family with sequence similarity 78 , member $\mathrm{B}$ gene $(F A M 78 B$, recessive model), rs6929846 $(\mathrm{T} \rightarrow \mathrm{C})$ of the butyrophilin, subfamily 2, member A1 gene (BTN2A1, dominant model), rs146021107 $(\mathrm{G} \rightarrow-)$ of the pancreatic and duodenal homeobox 1 gene (PDX1, dominant model) and $\operatorname{rs} 1671021(\mathrm{G} \rightarrow \mathrm{A})$ of the lethal giant larvae homolog 2 gene ( $L L G L 2$, dominant model) were significantly $(\mathrm{P}<0.05)$ associated with the prevalence of hypertension.

The association between the prevalence of hypertension and age analyzed longitudinally with a generalized estimating equation according to the SNP genotype is shown in Fig. 1. The prevalence of hypertension was greater in the combined group of subjects with the $T T$ or $T C$ genotypes of rs 2116519 of $F A M 78 B$ than in those with the $C C$ genotype from 40 to 90 years of age (Fig. 1A), in the combined group of subjects with the $C T$ or $T T$ genotypes of rs6929846 of BTN2Al than in those with the $C C$ genotype (Fig. 1B), in subjects with the $G G$ genotype of rs146021107 of $P D X 1$ than in the combined group of subjects with the G/- or -/- genotypes (Fig. 1C), and in the combined group of subjects with the $A G$ or $G G$ genotypes of rs1671021 of LLGL2 than in those with the $A A$ genotype (Fig. 1D).

Given that 4 SNPs were significantly associated with hypertension, the association of these SNPs with systolic, diastolic, or mean BP in all individuals or individuals not taking any anti-hypertensive medication were analyzed with a generalized linear mixed-effect model, with adjustment for age, gender, BMI and smoking status (Table VI). The rs6929846 polymorphism of BTN2Al was significantly associated with systolic, diastolic and mean BP in the dominant model among all individuals or individuals not taking any anti-hypertensive 
Table III. Characteristics of the study subjects: analysis of all measurements in a 5-year follow-up.

\begin{tabular}{|c|c|c|c|}
\hline Parameter & Male $^{\mathrm{a}}$ & Female $^{\mathrm{a}}$ & $\mathrm{All}^{\mathrm{a}}$ \\
\hline No. of subjects & 3352 & 2675 & 6027 \\
\hline Age (years) & $52.5 \pm 12.5(15,959)$ & $52.5 \pm 11.9(12,572)$ & $52.5 \pm 12.2(28,531)$ \\
\hline Height (cm) & $168.4 \pm 6.6(15,550)$ & $155.2 \pm 5.9(12,373)$ & $162.6 \pm 9.1(27,923)$ \\
\hline Weight $(\mathrm{kg})$ & $67.0 \pm 11.0(15,548)$ & $53.5 \pm 8.2(12,373)$ & $61.0 \pm 12.0(27,921)$ \\
\hline Body mass index $\left(\mathrm{kg} / \mathrm{m}^{2}\right)$ & $23.6 \pm 3.3(15,548)$ & $22.2 \pm 3.2(12,373)$ & $23.0 \pm 3.3(27,921)$ \\
\hline Waist circumference $(\mathrm{cm})$ & $83.2 \pm 8.7(11,817)$ & $77.8 \pm 9.0(9,541)$ & $80.8 \pm 9.2(21,358)$ \\
\hline Alcohol concumption (\%) & $67.4(15,959)$ & $26.4(12,572)$ & $49.3(28,531)$ \\
\hline Current or former smoker (\%) & $65.0(15,959)$ & $8.5(12,572)$ & $40.1(28,531)$ \\
\hline Systolic blood pressure $(\mathrm{mmHg})$ & $122 \pm 16(15,541)$ & $119 \pm 16(12,370)$ & $121 \pm 16(27,911)$ \\
\hline Diastolic blood pressure (mmHg) & $77 \pm 12(15,541)$ & $71 \pm 11(12,370)$ & $75 \pm 12(27,911)$ \\
\hline Mean blood pressure $(\mathrm{mmHg})$ & $92 \pm 13(15,541)$ & $87 \pm 12(12,370)$ & $90 \pm 13(27,911)$ \\
\hline Ocular tension (right, $\mathrm{mmHg}$ ) & $14.0 \pm 3.0(6,132)$ & $13.4 \pm 2.8(4,886)$ & $13.7 \pm 3.0(11,018)$ \\
\hline Functional vital capacity (1) & $3.53 \pm 0.66(6,173)$ & $2.55 \pm 0.47(4,865)$ & $3.10 \pm 0.76(11,038)$ \\
\hline FEV1\% (\%) & $82.3 \pm 7.1(6,168)$ & $84.8 \pm 6.7(4,865)$ & $83.4 \pm 7.0(11,033)$ \\
\hline Serum albumin $(\mathrm{g} / \mathrm{l})$ & $44.5 \pm 2.9(10,332)$ & $44.1 \pm 2.7(8,510)$ & $44.3 \pm 2.8(18,842)$ \\
\hline Serum total cholesterol $(\mathrm{mmol} / \mathrm{l})$ & $5.15 \pm 0.88(15,121)$ & $5.31 \pm 0.88(11,887)$ & $5.22 \pm 0.89(27,008)$ \\
\hline Serum triglyceride $(\mathrm{mmol} / \mathrm{l})$ & $1.46 \pm 1.06(15,639)$ & $1.01 \pm 0.58(12,401)$ & $1.26 \pm 0.91(28,040)$ \\
\hline Serum HDL-cholesterol (mmol/l) & $1.47 \pm 0.39(15,627)$ & $1.78 \pm 0.42(12,378)$ & $1.61 \pm 0.43(28,005)$ \\
\hline Serum LDL-cholesterol (mmol/l) & $3.19 \pm 0.81(14,997)$ & $3.18 \pm 0.79(11,836)$ & $3.18 \pm 0.80(26,833)$ \\
\hline Fasting plasma glucose $(\mathrm{mmol} / \mathrm{l})$ & $5.82 \pm 1.27(15,685)$ & $5.39 \pm 0.93(12,395)$ & $5.63 \pm 1.15(28,080)$ \\
\hline Blood hemoglobin A1c (\%) & $5.78 \pm 0.74(10,849)$ & $5.64 \pm 0.54(10,169)$ & $5.71 \pm 0.66(21,018)$ \\
\hline Blood urea nitrogen $(\mathrm{mmol} / \mathrm{l})$ & $5.61 \pm 2.86(8,889)$ & $5.07 \pm 2.28(8,162)$ & $5.36 \pm 2.61(17,051)$ \\
\hline Serum creatinine $(\mu \mathrm{mol} / \mathrm{l})$ & $88.3 \pm 116.2(14,545)$ & $63.1 \pm 82.5(11,225)$ & $77.3 \pm 103.6(25,770)$ \\
\hline eGFR $\left(\mathrm{ml} / \mathrm{min} / 1.73 \mathrm{~m}^{-2}\right)$ & $77.2 \pm 18.0(14,545)$ & $80.3 \pm 17.5(11,225)$ & $78.5 \pm 17.9(25,770)$ \\
\hline Serum uric acid $(\mu \mathrm{mol} / \mathrm{l})$ & $372 \pm 79(14,368)$ & $273 \pm 62(10,900)$ & $329 \pm 87(25,268)$ \\
\hline Serum C-reactive protein $(\mu \mathrm{g} / \mathrm{l})$ & $1573 \pm 6428(5,793)$ & $1207 \pm 4107(4,938)$ & $1405 \pm 5486(10,731)$ \\
\hline White blood cells $\left(10^{3} / \mu 1\right)$ & $5.94 \pm 1.73(12,521)$ & $5.03 \pm 1.45(9,419)$ & $5.55 \pm 1.68(21,940)$ \\
\hline Red blood cells $\left(10^{4} / \mu \mathrm{l}\right)$ & $461 \pm 46(12,651)$ & $415 \pm 36(9,500)$ & $441 \pm 47(22,151)$ \\
\hline Hemoglobin $(\mathrm{g} / \mathrm{l})$ & $147 \pm 13(12,651)$ & $127 \pm 13(9,501)$ & $139 \pm 16(22,152)$ \\
\hline Hematocrit (\%) & $43.3 \pm 3.7(12,642)$ & $37.5 \pm 3.4(9,497)$ & $40.8 \pm 4.6(22,139)$ \\
\hline Platelets $(104 / \mu 1)$ & $23.1 \pm 5.5(12,473)$ & $23.8 \pm 6.2(9,398)$ & $23.4 \pm 5.8(21,871)$ \\
\hline
\end{tabular}

${ }^{a}$ Values in parentheses indicate the numbers of measurements taken. Quantitative data are the means \pm SD. FEV $1 \%$, forced expiratory volume in 1 sec percentage; HDL, high density lipoprotein; LDL, low density lipoprotein; eGFR, estimated glomerular filtration rate $\left(\mathrm{ml} / \mathrm{min} / 1.73 \mathrm{~m}^{-2}\right)=194 \mathrm{x}$ [age $\left.(\mathrm{years})\right]^{-0.287} \mathrm{x}[\mathrm{serum}$ creatinine $(\mathrm{mg} / \mathrm{dl})]^{-1.094} \times[0.739$ if female $]$.

medication, with the $T$ allele being associated with an increased BP. The rs146021107 SNP of PDX1 was significantly associated with systolic BP in the dominant model among all individuals or individuals not taking any anti-hypertensive medication, with the $G$ allele being associated with an increased BP. The rs2116519 polymorphism of $F A M 78 B$ was significantly associated with diastolic BP in the recessive model among individuals not taking any anti-hypertensive medication, with the $T$ allele being associated with a high BP. The rs1671021 SNP of $L L G L 2$ was significantly associated with diastolic and mean BP in the dominant model among individuals not taking any antihypertensive medication, with the $G$ allele being associated with a high BP.

The association between systolic or diastolic BP and age in individuals not taking any anti-hypertensive medication was analyzed longitudinally according to genotype with a general- ized linear mixed-effect model (Fig. 2). Systolic (Fig. 2A) and diastolic (Fig. 2B) BP were greater in the combined group of individuals with the $C T$ or $T T$ genotypes of rs6929846 of $B T N 2 A 1$ than in those with the $C C$ genotype from 40 to 90 years of age. Systolic BP was greater in subjects with the $G G$ genotype of rs146021107 of PDX1 than in the combined group of individuals with the $G /$ - or -/- genotypes (Fig. 2C). Diastolic BP was greater in the combined group of individuals with the $A G$ or $G G$ genotypes of rs1671021 of $L L G L 2$ than in those with the $A A$ genotype (Fig. 2D).

\section{Discussion}

Given that genetic factors, as well as interactions between multiple genes and environmental factors are important in the development of hypertension (1), the ability to predict the risk 
Table IV. Characteristics of subjects with hypertension and controls: cross-sectional analysis in March 2014.

\begin{tabular}{|c|c|c|c|}
\hline Parameter & $\begin{array}{l}\text { Subjects with } \\
\text { hypertension }^{\text {a }}\end{array}$ & Controls $^{\mathrm{a}}$ & P-value \\
\hline No. of subjects & 2250 & 3777 & \\
\hline Age (years) & $61.1 \pm 10.7(2,250)$ & $50.1 \pm 12.4(3,777)$ & $<0.0001$ \\
\hline Gender (male/female, \%) & $62.6 / 37.4$ & $51.5 / 48.5$ & $<0.0001$ \\
\hline Height $(\mathrm{cm})$ & $161.3 \pm 9.4(2,207)$ & $163.2 \pm 9.0(3,747)$ & $<0.0001$ \\
\hline Weight $(\mathrm{kg})$ & $63.1 \pm 12.7(2,205)$ & $59.7 \pm 11.6(3,747)$ & $<0.0001$ \\
\hline Body mass index $\left(\mathrm{kg} / \mathrm{m}^{2}\right)$ & $24.1 \pm 3.6(2,205)$ & $22.3 \pm 3.1(3,747)$ & $<0.0001$ \\
\hline Waist circumference $(\mathrm{cm})$ & $84.0 \pm 9.5(1,986)$ & $78.5 \pm 8.5(3,619)$ & $<0.0001$ \\
\hline Alcohol consumption (\%) & $52.0(2,250)$ & $46.0(3,777)$ & $<0.0001$ \\
\hline Current or former smoker (\%) & $47.7(2,250)$ & $44.5(3,777)$ & 0.0147 \\
\hline Systolic blood pressure (mmHg) & $133 \pm 15(2,200)$ & $113 \pm 11(3,745)$ & $<0.0001$ \\
\hline Diastolic blood pressure (mmHg) & $83 \pm 12(2,200)$ & $70 \pm 10(3,745)$ & $<0.0001$ \\
\hline Mean blood pressure $(\mathrm{mmHg})$ & $99 \pm 12(2,200)$ & $84 \pm 9(3,745)$ & $<0.0001$ \\
\hline Ocular tension (right, $\mathrm{mmHg}$ ) & $13.9 \pm 3.0(722)$ & $13.3 \pm 2.9(1,339)$ & $<0.0001$ \\
\hline Functional vital capacity (1) & $3.12 \pm 0.80(768)$ & $3.39 \pm 0.80(1,475)$ & $<0.0001$ \\
\hline FEV1\% (\%) & $80.4 \pm 6.38(768)$ & $81.7 \pm 6.6(1,475)$ & $<0.0001$ \\
\hline Serum albumin $(\mathrm{g} / \mathrm{l})$ & $44.5 \pm 3.0(1,715)$ & $44.7 \pm 2.4(2,497)$ & 0.0302 \\
\hline Serum total cholesterol $(\mathrm{mmol} / \mathrm{l})$ & $5.19 \pm 0.90(2,230)$ & $5.23 \pm 0.88(3,720)$ & 0.0921 \\
\hline Serum triglyceride $(\mathrm{mmol} / \mathrm{l})$ & $1.43 \pm 0.96(2,215)$ & $1.16 \pm 0.79(3,721)$ & $<0.0001$ \\
\hline Serum HDL-cholesterol (mmol/1) & $1.59 \pm 0.44(2,213)$ & $1.70 \pm 0.45(3,721)$ & $<0.0001$ \\
\hline Serum LDL-cholesterol (mmol/l) & $3.15 \pm 0.79(2,212)$ & $3.19 \pm 0.81(3,720)$ & 0.0632 \\
\hline Fasting plasma glucose (mmol/l) & $5.90 \pm 1.36(2,238)$ & $5.40 \pm 0.96(3,718)$ & $<0.0001$ \\
\hline Blood hemoglobin A1c (\%) & $5.84 \pm 0.78(1,782)$ & $5.59 \pm 0.59(2,681)$ & $<0.0001$ \\
\hline Blood urea nitrogen (mmol/l) & $5.72 \pm 2.68(1,691)$ & $4.86 \pm 1.23(2,410)$ & $<0.0001$ \\
\hline Serum creatinine $(\mu \mathrm{mol} / \mathrm{l})$ & $88.5 \pm 127.4(2,162)$ & $64.8 \pm 15.1(3,414)$ & $<0.0001$ \\
\hline eGFR $\left(\mathrm{ml} / \mathrm{min} / 1.73 \mathrm{~m}^{-2}\right)$ & $71.2 \pm 18.3(2,162)$ & $80.1 \pm 14.7(3,414)$ & $<0.0001$ \\
\hline Serum uric acid $(\mu \mathrm{mol} / \mathrm{l})$ & $349 \pm 88(2,139)$ & $312 \pm 81(3,392)$ & $<0.0001$ \\
\hline Serum C-reactive protein $(\mu \mathrm{g} / \mathrm{l})$ & $1832 \pm 9666(775)$ & $826 \pm 3359(1,338)$ & 0.0005 \\
\hline White blood cells $\left(10^{3} / \mu 1\right)$ & $5.51 \pm 1.74(1,573)$ & $5.31 \pm 1.63(3,034)$ & 0.0001 \\
\hline Red blood cells $\left(10^{4} / \mu 1\right)$ & $436 \pm 48(1,577)$ & $437 \pm 43(3,046)$ & 0.1928 \\
\hline Hemoglobin $(\mathrm{g} / \mathrm{l})$ & $139 \pm 16(1,577)$ & $137 \pm 15(3,046)$ & 0.0017 \\
\hline Hematocrit (\%) & $40.4 \pm 4.4(1,576)$ & $40.1 \pm 4.2(3,042)$ & 0.0186 \\
\hline Platelets $\left(10^{4} / \mu 1\right)$ & $21.8 \pm 5.5(1,557)$ & $22.6 \pm 5.3(3,011)$ & $<0.0001$ \\
\hline
\end{tabular}

${ }^{a}$ Values in parentheses indicate the numbers of measurements taken. Quantitative data are the means \pm SD. eGFR, estimated glomerular filtration rate (ml/ $\left.\min / 1.73 \mathrm{~m}^{-2}\right)=194 \mathrm{x}$ [age (years) $]^{-0.287} \mathrm{x}$ [serum creatinine $\left.(\mathrm{mg} / \mathrm{dl})\right]^{-1.094} \mathrm{x}$ [0.739 if female]; HDL, high density lipoprotein; LDL, low density lipoprotein.

of developing hypertension on the basis of genetic variants would be beneficial for the personalized prevention of this condition. In this study, we demonstrated that rs6929846 ( $\mathrm{T} \rightarrow \mathrm{C}$ ) of BTN2Al was significantly associated with the prevalence of hypertension and also with systolic, diastolic, and mean BP in community-dwelling Japanese individuals, with the minor $T$ allele representing a risk factor for hypertension.

We have previously reported that rs6929846 of BTN2Al is significantly associated with hypertension in a cross-sectional study of a different hospital-based population (31). We also observed the association of this polymorphism with hypertension in a previous cross-sectional analysis of the Inabe Health and Longevity Study (26). The results of the present longitudinal population-based study are thus consistent with these previous observations $(26,31)$ and validate the association of rs6929846 of BTN2Al with hypertension.

$B T N 2 A 1$ is a cell-surface transmembrane glycoprotein and a member of the butyrophilin superfamily of proteins. Many of these proteins regulate immune function, and polymorphisms within the coding sequences of the corresponding genes have been associated with the predisposition to inflammatory diseases (32). We have previously demonstrated that the $T$ allele of rs6929846 of BTN2A1 is associated with an increased risk of developing myocardial infarction and with an increased transcriptional activity of BTN2A1 (15). The serum concentration of high-sensitivity $\mathrm{C}$-reactive protein was significantly greater in individuals in the combined group of $C T$ or $T T$ genotypes for this SNP than in those with the 
Table V. Association of polymorphisms with hypertension analyzed for 5-year longitudinal data with a generalized estimating equation.

\begin{tabular}{|c|c|c|c|c|c|c|}
\hline $\begin{array}{l}\text { Gene or } \\
\text { locus }\end{array}$ & SNP & Genotype & Hypertension $^{\mathrm{a}}$ & Controls $^{\mathrm{a}}$ & $\begin{array}{c}\text { P-value } \\
{(\text { dominant model })^{\mathrm{b}}}^{\mathrm{b}}\end{array}$ & $\begin{array}{c}\text { P-value } \\
\text { (recessive model) }^{\mathrm{c}}\end{array}$ \\
\hline$F A M 78 B$ & rs2116519 $(\mathrm{C} \rightarrow \mathrm{T})$ & $\begin{array}{l}T T \\
T C \\
C C\end{array}$ & $\begin{array}{c}1,888(32.3) \\
2,959(50.7) \\
991(17.0)\end{array}$ & $\begin{array}{r}6,649(30.3) \\
11,046(50.3) \\
4,279(19.5)\end{array}$ & 0.3039 & 0.0266 \\
\hline $3 q 28$ & rs9846911 $(A \rightarrow G)$ & $\begin{array}{l}A A \\
A G \\
G G\end{array}$ & $\begin{array}{c}5,033(86.2) \\
759(13.0) \\
46(0.8)\end{array}$ & $\begin{array}{c}19,102(86.9) \\
2,756(12.5) \\
116(0.5)\end{array}$ & 0.1629 & 0.1620 \\
\hline$A L P K 1$ & $\operatorname{rs} 2074379(\mathrm{G} \rightarrow \mathrm{A})$ & $\begin{array}{l}A A \\
A G \\
G G\end{array}$ & $\begin{array}{c}2,707(46.4) \\
2,560(43.9) \\
571(9.8)\end{array}$ & $\begin{array}{r}10,004(45.5) \\
9,736(44.3) \\
2,234(10.2)\end{array}$ & 0.7330 & 0.2596 \\
\hline$A L P K 1$ & rs2074380 $(\mathrm{G} \rightarrow \mathrm{A})$ & $\begin{array}{l}G G \\
G A \\
A A\end{array}$ & $\begin{array}{c}4,905(84.0) \\
885(15.2) \\
48(0.8)\end{array}$ & $\begin{array}{c}18,656(84.9) \\
3,165(14.4) \\
153(0.7)\end{array}$ & 0.1124 & 0.1496 \\
\hline$A L P K 1$ & rs2074381 $(A \rightarrow G)$ & $\begin{array}{l}A A \\
A G \\
G G\end{array}$ & $\begin{array}{c}4,981(85.3) \\
821(14.1) \\
36(0.6)\end{array}$ & $\begin{array}{c}18,815(85.6) \\
3,038(13.8) \\
121(0.6)\end{array}$ & 0.2390 & 0.4732 \\
\hline$A L P K 1$ & rs2074388 $(\mathrm{G} \rightarrow \mathrm{A})$ & $\begin{array}{l}A A \\
A G \\
G G\end{array}$ & $\begin{array}{c}2,714(46.5) \\
2,552(43.7) \\
572(9.8)\end{array}$ & $\begin{array}{r}10,013(45.6) \\
9,721(44.2) \\
2,240(10.2)\end{array}$ & 0.7043 & 0.2637 \\
\hline$B T N 2 A 1$ & rs6929846 $(\mathrm{T} \rightarrow \mathrm{C})$ & $\begin{array}{l}C C \\
C T \\
T T\end{array}$ & $\begin{array}{c}4,484(76.8) \\
1,275(21.8) \\
79(1.4)\end{array}$ & $\begin{array}{c}17,333(78.9) \\
4,365(19.9) \\
276(1.3)\end{array}$ & 0.0013 & 0.3602 \\
\hline THBS2 & $\operatorname{rs} 8089(T \rightarrow G)$ & $\begin{array}{l}T T \\
T G \\
G G\end{array}$ & $\begin{array}{c}4,895(83.8) \\
902(15.5) \\
41(0.7)\end{array}$ & $\begin{array}{c}18,159(82.6) \\
3,615(16.5) \\
200(0.9)\end{array}$ & 0.7407 & 0.9741 \\
\hline$P D X 1$ & $\operatorname{rs} 146021107(\mathrm{G} \rightarrow-)$ & $\begin{array}{l}G G \\
G /- \\
-/-\end{array}$ & $\begin{array}{l}1,745(29.9) \\
2,839(48.6) \\
1,254(21.5)\end{array}$ & $\begin{array}{r}5,983(27.2) \\
11,049(50.3) \\
4,942(22.5)\end{array}$ & 0.0031 & 0.2885 \\
\hline$F 7$ & $\operatorname{rs} 6046(\mathrm{G} \rightarrow \mathrm{A})$ & $\begin{array}{l}G G \\
G A \\
A A\end{array}$ & $\begin{array}{c}5,104(87.4) \\
715(12.2) \\
19(0.3)\end{array}$ & $\begin{array}{c}19,187(87.3) \\
2,693(12.3) \\
94(0.4)\end{array}$ & 0.1478 & 0.8979 \\
\hline$L L G L 2$ & $\operatorname{rs} 1671021(G \rightarrow A)$ & $\begin{array}{l}A A \\
A G \\
G G\end{array}$ & $\begin{array}{c}4,187(71.7) \\
1,521(26.1) \\
130(2.2)\end{array}$ & $\begin{array}{c}16,353(74.4) \\
5,223(23.8) \\
398(1.8)\end{array}$ & 0.0372 & 0.3881 \\
\hline$I L F 3$ & $\operatorname{rs} 2569512(\mathrm{G} \rightarrow \mathrm{A})$ & $\begin{array}{l}G G \\
G A \\
A A\end{array}$ & $\begin{array}{r}2,563(43.9) \\
2,605(44.6) \\
670(11.5)\end{array}$ & $\begin{array}{r}9,525(43.3) \\
10,180(46.3) \\
2,269(10.3)\end{array}$ & 0.3765 & 0.2560 \\
\hline CELSR1 & rs6007897 $(\mathrm{C} \rightarrow \mathrm{T})$ & $\begin{array}{l}T T \\
T C \\
C C\end{array}$ & $\begin{array}{c}5,671(97.1) \\
167(2.9) \\
0(0)\end{array}$ & $\begin{array}{c}21,303(96.9) \\
671(3.1) \\
0(0)\end{array}$ & 0.6353 & not determined \\
\hline
\end{tabular}

The prevalence of hypertension was compared between 2 groups (the dominant or recessive model) for each polymorphism with adjustment for age, gender, body mass index and smoking status. ${ }^{a}$ Values indicate the numbers of measurements taken, with the percentages in parentheses; ${ }^{\mathrm{b}} \mathrm{dominant}$ model: $A A$ vs. $A B+$

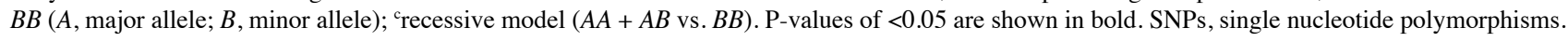

CC genotype among healthy subjects without neoplastic, infectious, or inflammatory disease $(15,33)$. These observations suggest that the $T$ allele of rs6929846 of BTN2Al may accelerate inflammatory processes.
Previous studies have suggested that chronic vascular inflammation influences BP and vascular remodeling (34-37). Systolic and diastolic BP, as well as pulse pressure were thus found to be positively associated with the plasma concentration 

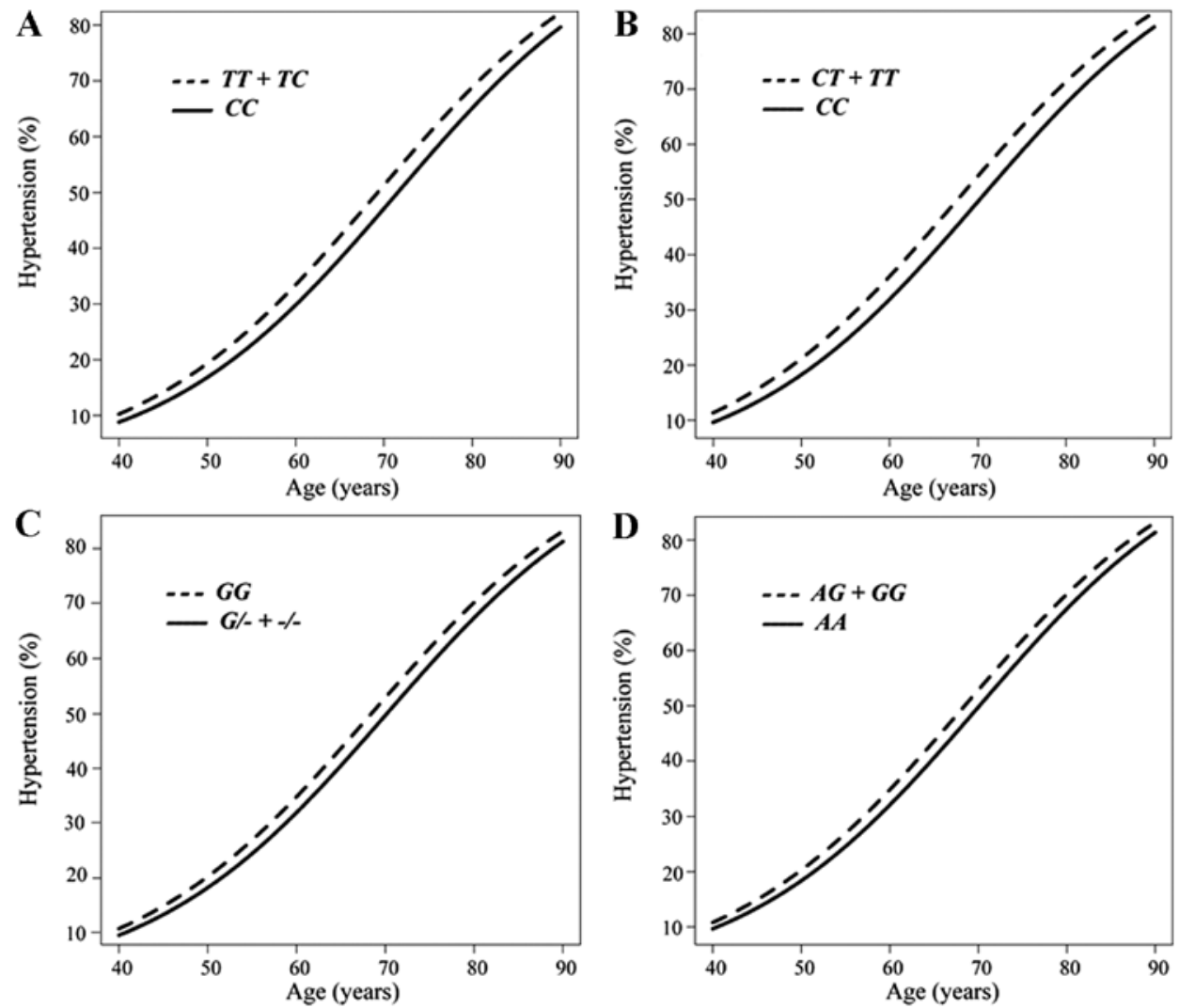

Figure 1. Longitudinal analysis with a generalized estimating equation of the association between the prevalence of hypertension and age according to the genotype for (A) rs2116519 of $F A M 78 B$ (TT + TC vs. CC), (B) rs6929846 of BTN2A1 (CC vs. $C T+T T)$ (B), (C) rs146021107 of $P D X 1$ (GG vs. G/- + -/-), or (D) rs1671021 of $L L G L 2(A A$ vs. $A G+G G)$.
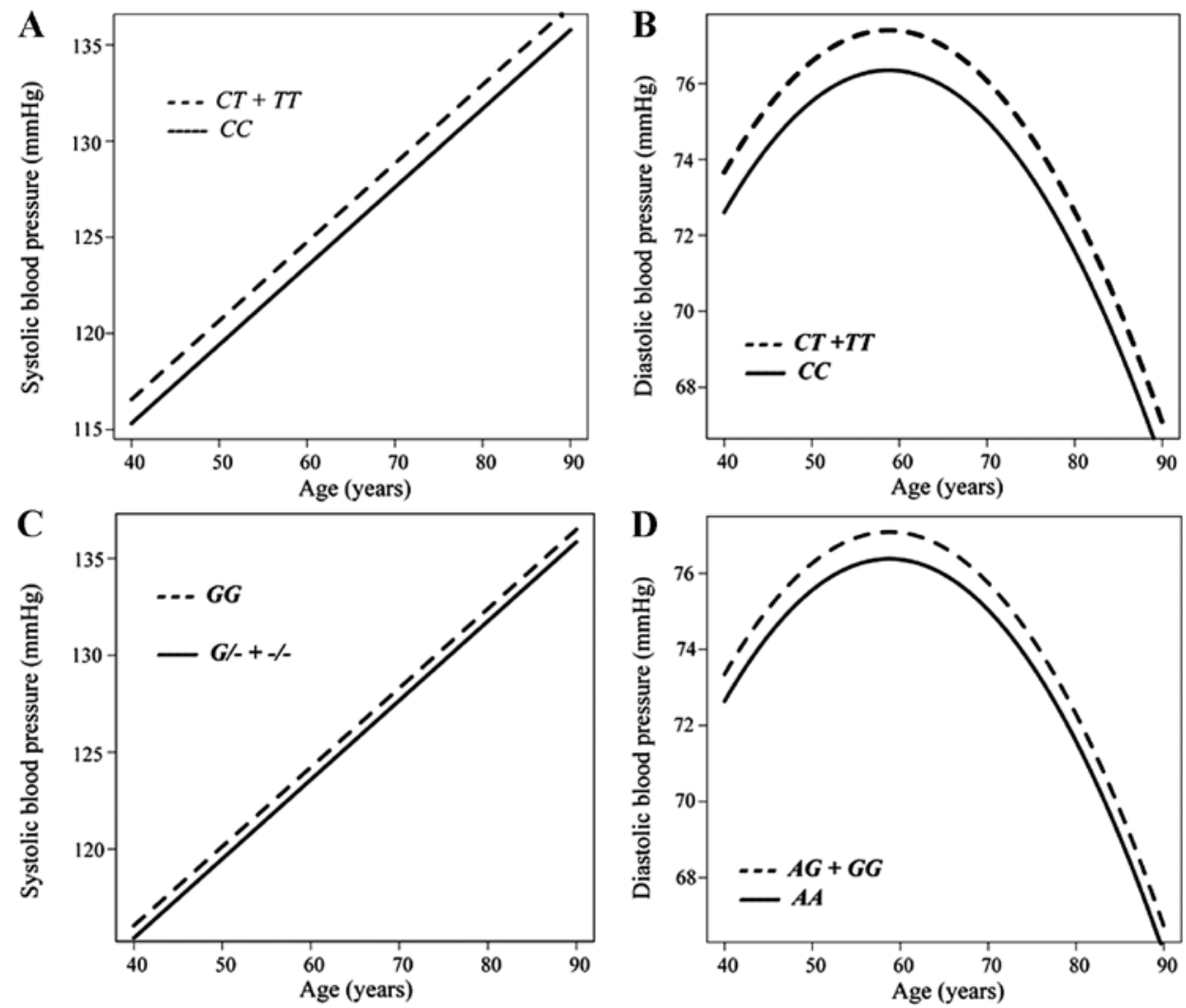

Figure 2. Longitudinal analysis with a generalized linear mixed-effect model of the association between (A) systolic or (B) diastolic blood pressure (BP) and age according to genotype for rs6929846 of BTN2A1 (CC vs. $C T+T T$ ), (C) between systolic BP and age according to genotype for rs146021107 of PDXI ( $G G$ vs. $G /-+-/-$ ), or (D) between diastolic BP and age according to genotype for rs1671021 of $L L G L 2(A A$ vs. $A G+G G)$ among individuals not taking any anti-hypertensive medication. 
Table VI. Association of polymorphisms with systolic, diastolic, or mean BP in all individuals or individuals not taking any anti-hypertensive medication analyzed for 5-year longitudinal data with a generalized linear mixed-effect model.

\begin{tabular}{|c|c|c|c|c|c|c|c|c|}
\hline Gene & SNP & $\mathrm{BP}(\mathrm{mmHg})$ & \multicolumn{2}{|c|}{ Dominant model $^{\mathrm{a}}$} & P-value & \multicolumn{2}{|c|}{ Recessive model $^{\mathrm{a}}$} & P-value \\
\hline \multicolumn{9}{|c|}{ All individuals } \\
\hline \multirow[t]{4}{*}{$F A M 78 B$} & rs2116519 $(\mathrm{C} \rightarrow \mathrm{T})$ & & $T T(8,537)$ & $T C+C C(19,275)$ & & $T T+T C(2,2542)$ & $C C(5,270)$ & \\
\hline & & Systolic & $121.0 \pm 16.7$ & $120.4 \pm 16.1$ & 0.3818 & $120.7 \pm 16.5$ & $120.1 \pm 15.7$ & 0.5823 \\
\hline & & Diastolic & $74.9 \pm 12.5$ & $74.6 \pm 12.1$ & 0.1260 & $74.8 \pm 12.4$ & $74.1 \pm 11.8$ & 0.0823 \\
\hline & & Mean & $90.2 \pm 13.1$ & $89.9 \pm 12.6$ & 0.1722 & $90.1 \pm 12.9$ & $89.4 \pm 12.2$ & 0.1814 \\
\hline \multirow[t]{4}{*}{$B T N 2 A 1$} & rs6929846 $(\mathrm{T} \rightarrow \mathrm{C})$ & & $C C(21,817)$ & $C T+T T(5,995)$ & & $C C+C T(27,457)$ & $T T(355)$ & \\
\hline & & Systolic & $120.4 \pm 16.2$ & $121.2 \pm 16.7$ & 0.0061 & $120.6 \pm 16.3$ & $121.4 \pm 15.4$ & 0.1369 \\
\hline & & Diastolic & $74.5 \pm 12.2$ & $75.2 \pm 12.4$ & 0.0023 & $74.7 \pm 12.3$ & $75.2 \pm 11.0$ & 0.2483 \\
\hline & & Mean & $89.8 \pm 12.7$ & $90.5 \pm 13.0$ & 0.0019 & $90.0 \pm 12.8$ & $90.6 \pm 11.7$ & 0.1748 \\
\hline \multirow[t]{4}{*}{$P D X 1$} & rs $146021107(\mathrm{G} \rightarrow-)$ & & $G G(7,728)$ & $G /-+-/-(20,084)$ & & $G G+G /-(21,616)$ & $-/-(6,196)$ & \\
\hline & & Systolic & $121.1 \pm 17.1$ & $120.4 \pm 16.0$ & 0.0284 & $120.8 \pm 16.4$ & $120.0 \pm 16.1$ & 0.3884 \\
\hline & & Diastolic & $74.5 \pm 12.8$ & $74.7 \pm 12.1$ & 0.2719 & $74.8 \pm 12.3$ & $74.4 \pm 12.1$ & 0.9222 \\
\hline & & Mean & $90.1 \pm 13.3$ & $90.0 \pm 12.5$ & 0.1029 & $90.1 \pm 12.8$ & $89.6 \pm 12.5$ & 0.6821 \\
\hline \multirow[t]{4}{*}{$L L G L 2$} & $\operatorname{rs} 1671021(\mathrm{G} \rightarrow \mathrm{A})$ & & $A A(20,540)$ & $A G+G G(7,272)$ & & $A A+A G(27,284)$ & $G G(528)$ & \\
\hline & & Systolic & $120.4 \pm 16.2$ & $121.2 \pm 16.6$ & 0.1943 & $120.6 \pm 16.3$ & $121.6 \pm 16.1$ & 0.9056 \\
\hline & & Diastolic & $74.5 \pm 12.2$ & $75.2 \pm 12.4$ & 0.1280 & $74.7 \pm 12.3$ & $75.8 \pm 12.7$ & 0.4665 \\
\hline & & Mean & $89.8 \pm 12.7$ & $90.5 \pm 12.9$ & 0.1315 & $90.0 \pm 12.8$ & $91.1 \pm 12.8$ & 0.7203 \\
\hline \multicolumn{9}{|c|}{ Individuals not taking any anti-hypertensive medication } \\
\hline \multirow[t]{4}{*}{ FAM78B } & rs2116519 $(\mathrm{C} \rightarrow \mathrm{T})$ & & $T T(8,132)$ & $T C+C C(18,370)$ & & $T T+T C(2,1459)$ & $C C(5,043)$ & \\
\hline & & Systolic & $120.5 \pm 16.7$ & $119.9 \pm 16.0$ & 0.2563 & $120.2 \pm 16.4$ & $119.7 \pm 15.6$ & 0.5041 \\
\hline & & Diastolic & $74.6 \pm 12.5$ & $74.4 \pm 12.1$ & 0.2039 & $74.6 \pm 12.4$ & $73.9 \pm 11.7$ & 0.0495 \\
\hline & & Mean & $89.9 \pm 13.0$ & $89.6 \pm 12.6$ & 0.1948 & $89.8 \pm 12.9$ & $89.1 \pm 12.1$ & 0.1248 \\
\hline \multirow[t]{4}{*}{$B T N 2 A 1$} & rs6929846 $(\mathrm{T} \rightarrow \mathrm{C})$ & & $C C(20,807)$ & $C T+T T(5,695)$ & & $C C+C T(26,163)$ & $T T$ (339) & \\
\hline & & Systolic & $120.0 \pm 16.1$ & $120.7 \pm 16.6$ & 0.0017 & $120.1 \pm 16.3$ & $120.8 \pm 15.3$ & 0.1734 \\
\hline & & Diastolic & $74.3 \pm 12.2$ & $75.0 \pm 12.4$ & 0.0008 & $74.4 \pm 12.3$ & $75.0 \pm 10.8$ & 0.2059 \\
\hline & & Mean & $89.5 \pm 12.7$ & $90.2 \pm 13.0$ & 0.0005 & $89.7 \pm 12.7$ & $90.3 \pm 11.5$ & 0.1678 \\
\hline \multirow[t]{4}{*}{$P D X 1$} & rs $146021107(\mathrm{G} \rightarrow-)$ & & $G G(7,328)$ & $G /-+-/-(19,174)$ & & $G G+G /-(20,580)$ & $-/-(5,922)$ & \\
\hline & & Systolic & $120.6 \pm 17.1$ & $120.0 \pm 15.9$ & 0.0132 & $120.3 \pm 16.3$ & $119.5 \pm 16.0$ & 0.2565 \\
\hline & & Diastolic & $74.2 \pm 12.8$ & $74.5 \pm 12.0$ & 0.3963 & $74.5 \pm 12.3$ & $74.2 \pm 12.1$ & 0.8832 \\
\hline & & Mean & $89.7 \pm 13.3$ & $89.7 \pm 12.5$ & 0.1081 & $89.8 \pm 12.8$ & $89.3 \pm 12.5$ & 0.7018 \\
\hline \multirow[t]{4}{*}{$L L G L 2$} & $\operatorname{rs} 1671021(\mathrm{G} \rightarrow \mathrm{A})$ & & $A A(19,569)$ & $A G+G G(6,933)$ & & $A A+A G(26,005)$ & $G G(497)$ & \\
\hline & & Systolic & $119.9 \pm 16.2$ & $120.7 \pm 16.5$ & 0.0891 & $120.1 \pm 16.3$ & $121.4 \pm 16.1$ & 0.6847 \\
\hline & & Diastolic & $74.2 \pm 12.2$ & $75.0 \pm 12.4$ & 0.0468 & $74.4 \pm 12.2$ & $75.7 \pm 12.7$ & 0.2512 \\
\hline & & Mean & $89.5 \pm 12.7$ & $90.2 \pm 12.9$ & 0.0471 & $89.6 \pm 12.7$ & $90.9 \pm 12.80$ & 0.3889 \\
\hline
\end{tabular}

Systolic, diastolic, or mean BP was compared between 2 groups (the dominant or recessive model) for each polymorphism with adjustment for age, gender, body mass index and smoking status. ${ }^{a}$ Values in parentheses indicate the numbers of measurements taken. Data for BP are the means \pm SD. P-values of $<0.05$ are shown in bold. BP, blood pressure. SNPs, single nucleotide polymorphisms.

of interleukin-6 in healthy men (34). The plasma concentration of high-sensitivity C-reactive protein was also greater in individuals with hypertension than in the controls, and it was shown to be positively associated with systolic BP and pulse pressure (35). In addition, oxidative stress and vascular inflammation have been shown to influence BP, suggesting that chronic inflammation may play a key role in the pathogenesis of hypertension $(36,37)$. In this study, we demonstrated that rs6929846 of BTN2A1 was significantly associated with hypertension, with the minor $T$ allele representing a risk factor for this condition. The enhancement of chronic inflammation by the $T$ allele of rs6929846 may account for its association with hypertension, although the molecular mechanisms underlying the effects of this polymorphism on the development of hypertension remain to be elucidated.

In a previous meta-analysis of cohort studies, a reduction of $10 \mathrm{mmHg}$ in systolic or $5 \mathrm{mmHg}$ in diastolic BP was estimated to result in a $22-25 \%$ decrease in the incidence of coronary artery disease and a 36-41\% decrease in that of stroke (38). In our longitudinal analysis, systolic, diastolic and mean BP were 
each increased by $1 \mathrm{mmHg}$ in individuals with the TT genotype of rs6929846 of BTN2A1 compared with those with the $C C$ genotype. Such a difference is small at the individual level and may not have practical clinical implications. However, even small increments in BP have important effects on cardiovascular morbidity and mortality at the population level, given the high incidence of coronary artery disease, stroke and chronic kidney disease. The reduction in the mortality rate estimated for each 2-mmHg decrease in systolic BP is $4 \%$ for coronary artery disease and $6 \%$ for stroke (39). Small differences in average $\mathrm{BP}$ at the population level thus result in significant differences in the population mortality rate (39).

In this study, we observed that the SNPs of PDX1, LLGL2 and $F A M 78 B$ were also associated with the prevalence of hypertension, as well as with systolic BP among all individuals and individuals not taking any anti-hypertensive medication (PDX1), with diastolic and mean BP among individuals without anti-hypertensive medication (LLGL2), or with diastolic BP among individuals without anti-hypertensive medication $(F A M 78 B)$. FAM78B is located at 1q24.1, which has previously been suggested to harbor susceptibility loci for hypertension (40) and type 2 diabetes mellitus (41), although the function of the gene remains unclear. $P D X 1$ is a transcriptional activator at several genes, including those for insulin, somatostatin, glucokinase, islet amyloid polypeptide and glucose transporter type 2 (NCBI Gene). It contributes to the early development of the pancreas and plays an important role in the glucose-dependent regulation of insulin gene expression (42). A rare frameshift variant of $P D X 1$ was previously found to associated with type 2 diabetes mellitus (43). We have previously demonstrated that rs146021107 of PDX1 is significantly associated with myocardial infarction $(18,20)$, although, to the best of our knowledge, the association of $P D X 1$ polymorphisms with hypertension has not yet been reported. $L L G L 2$ plays a role in asymmetric cell division, the establishment of epithelial cell polarity and cell migration $(44,45)$. We have previously demonstrated that rs1671021 of $L L G L 2$ is associated with ischemic stroke (16), although, to the best of our knowledge, variants of $L L G L 2$ have not yet been associated with hypertension.

The present study had certain limitations: i) given that the study subjects comprised only Japanese individuals, further studies are required on other ethnic groups. ii) It is possible that rs6929846 of BTN2A1 is in linkage disequilibrium with other polymorphisms in $B T N 2 A l$ or in nearby genes that are actually responsible for the development of hypertension. iii) The functional relevance of rs6929846 of BTN2A1 to the pathogenesis of hypertension remains unclear.

In conclusion, the present results suggest that BTN2A1 is a susceptibility gene for essential hypertension in Japanese individuals. The determination of the genotype for rs6929846 may prove informative for the assessment of the genetic risk for hypertension in such individuals.

\section{Acknowledgements}

This study was supported by the CREST, Japan Science and Technology Agency (to Y.Y. and I.T.), and by a Grant-in-Aid for Scientific Research from the Ministry of Education, Culture, Sports, Science and Technology of Japan (no. 24590746 to Y.Y.).

\section{References}

1. Lifton RP, Gharavi AG and Geller DS: Molecular mechanisms of human hypertension. Cell 104: 545-556, 2001.

2. Kupper N, Willemsen G, Riese H, Posthuma D, Boomsma DI and de Geus EJ: Heritability of daytime ambulatory blood pressure in an extended twin design. Hypertension 45: 80-85, 2005.

3. Agarwal A, Williams GH and Fisher ND: Genetics of human hypertension. Trends Endocrinol Metab 16: 127-133, 2005.

4. Kannel WB: Elevated systolic blood pressure as a cardiovascular risk factor. Am J Cardiol 85: 251-255, 2000

5. Sacco RL, Benjamin EJ, Broderick JP, Dyken M, Easton JD, Feinberg WM, Goldstein LB, Gorelick PB, Howard G, Kittner SJ, et al: American Heart Association Prevention Conference. IV. Prevention and Rehabilitation of Stroke. Risk factors. Stroke 28: 1507-1517, 1997.

6. Yamagata K, Ishida K, Sairenchi T, Takahashi H, Ohba S, Shiigai T, Narita $\mathrm{M}$ and Koyama A: Risk factors for chronic kidney disease in a community-based population: A 10-year follow-up study. Kidney Int 71: 159-166, 2007.

7. Ehret GB, Munroe PB, Rice KM, Bochud M, Johnson AD, Chasman DI, Smith AV, Tobin MD, Verwoert GC, Hwang SJ, et al; CHARGE-HF consortium: Genetic variants in novel pathways influence blood pressure and cardiovascular disease risk. Nature 478: 103-109, 2011.

8. Wain LV, Verwoert GC, O'Reilly PF, Shi G, Johnson T, Johnson AD, Bochud M, Rice KM, Henneman P, Smith AV, et al: Genome-wide association study identifies six new loci influencing pulse pressure and mean arterial pressure. Nat Genet 43: 1005-1011, 2011.

9. Newton-Cheh C, Johnson T, Gateva V, Tobin MD, Bochud M, Coin L, Najjar SS, Zhao JH, Heath SC, Eyheramendy S, et al: Genome-wide association study identifies eight loci associated with blood pressure. Nat Genet 41: 666-676, 2009.

10. Levy D, Ehret GB, Rice K, Verwoert GC, Launer LJ, Dehghan A, Glazer NL, Morrison AC, Johnson AD, Aspelund T, et al: Genome-wide association study of blood pressure and hypertension. Nat Genet 41: 677-687, 2009.

11. Wellcome Trust Case Control Consortium: Genome-wide association study of 14,000 cases of seven common diseases and 3,000 shared controls. Nature 447: 661-678, 2007.

12. Adeyemo A, Gerry N, Chen G, Herbert A, Doumatey A, Huang H, Zhou J, Lashley K, Chen Y, Christman M, et al: A genome-wide association study of hypertension and blood pressure in African Americans. PLoS Genet 5: e1000564, 2009.

13. Kato N, Miyata T, Tabara Y, Katsuya T, Yanai K, Hanada H, Kamide K, Nakura J, Kohara K, Takeuchi F, et al: High-density association study and nomination of susceptibility genes for hypertension in the Japanese National Project. Hum Mol Genet 17: 617-627, 2008

14. Tabara Y, Kohara K, Kita Y, Hirawa N, Katsuya T, Ohkubo T, Hiura Y, Tajima A, Morisaki T, Miyata T, et al; Global Blood Pressure Genetics Consortium: Common variants in the ATP2B1 gene are associated with susceptibility to hypertension: The Japanese Millennium Genome Project. Hypertension 56: 973-980, 2010.

15. Yamada Y, Nishida T, Ichihara S, Sawabe M,Fuku N, Nishigaki Y, Aoyagi Y, Tanaka M, Fujiwara Y, Yoshida H, et al: Association of a polymorphism of $B T N 2 A 1$ with myocardial infarction in East Asian populations. Atherosclerosis 215: 145-152, 2011.

16. Yamada Y, Fuku N, Tanaka M, Aoyagi Y, Sawabe M, Metoki N, Yoshida H, Satoh K, Kato K, Watanabe S, et al: Identification of CELSRI as a susceptibility gene for ischemic stroke in Japanese individuals by a genome-wide association study. Atherosclerosis 207: 144-149, 2009.

17. Yamada Y, Nishida T, Ichihara S, Kato K, Fujimaki T, Oguri M, Horibe H, Yoshida T, Watanabe S, Satoh K, et al: Identification of chromosome 3q28 and $A L P K 1$ as susceptibility loci for chronic kidney disease in Japanese individuals by a genome-wide association study. J Med Genet 50: 410-418, 2013.

18. Yamada Y, Matsuo H, Segawa T, Watanabe S, Kato K, Hibino T, Yokoi K, Ichihara S, Metoki N, Yoshida H, et al: Assessment of genetic risk for myocardial infarction. Thromb Haemost 96: 220-227, 2006.

19. Fujimaki T, Kato K, Yoshida T, Oguri M, Watanabe S, Metoki N, Yoshida H, Satoh K, Aoyagi Y, Nishigaki Y, et al: Association of genetic variants with myocardial infarction in Japanese individuals with chronic kidney disease. Thromb Haemost 101: 963-968, 2009. 
20. Oguri M, Kato K, Yokoi K, Itoh T, Yoshida T, Watanabe S, Metoki N, Yoshida H, Satoh K, Aoyagi Y, et al: Association of genetic variants with myocardial infarction in Japanese individuals with metabolic syndrome. Atherosclerosis 206: 486-493, 2009.

21. Ueyama C, Horibe H, Fujimaki T, Oguri M, Kato K and Yamada Y: Association of genetic variants of CELSR1 and 3q28 with hypertension in community-dwelling individuals. Biomed Rep 1: 840-844, 2013

22. Shimokata S, Oguri M, Fujimaki T, Horibe H, Kato K and Yamada Y: Association between polymorphisms of the $\alpha$-kinase 1 gene and type 2 diabetes mellitus in communitydwelling individuals. Biomed Rep 1: 940-944, 2013.

23. Oguri M, Fujimaki T, Horibe H, Kato K, Ichihara S and Yamada Y: Association of a polymorphism of BTN2Al with chronic kidney disease in community-dwelling individuals. Biomed Rep 1 : 868-872, 2013.

24. Fujimaki T,Horibe H, Oguri M,Kato K and Yamada Y: Association of genetic variants of the $\alpha$-kinase 1 gene with myocardial infarction in community-dwelling individuals. Biomed Rep 2: 127-131, 2014.

25. Horibe H, Ueyama C, Fujimaki T, Oguri M, Kato K, Ichihara $\mathrm{S}$ and Yamada Y: Association of a polymorphism of BTN2A1 with dyslipidemia in community-dwelling individuals. Mol Med Rep 9: 808-812, 2014

26. Murakata Y, Fujimaki T and Yamada Y: Association of a butyrophilin, subfamily 2, member A1 gene polymorphism with hypertension. Biomed Rep 2: 818-822, 2014.

27. Perloff D, Grim C, Flack J, Frohlich ED, Hill M, McDonald M and Morgenstern BZ: Human blood pressure determination by sphygmomanometry. Circulation 88: 2460-2470, 1993.

28. Itoh Y, Mizuki N, Shimada T, Azuma F, Itakura M, Kashiwase K, Kikkawa E, Kulski JK, Satake M and Inoko H: High-throughput DNA typing of HLA-A, -B, -C, and -DRB1 loci by a PCR-SSOPLuminex method in the Japanese population. Immunogenetics 57: 717-729, 2005

29. Hanley JA, Negassa A, Edwardes MD and Forrester JE: Statistical analysis of correlated data using generalized estimating equations: An orientation. Am J Epidemiol 157: 364-375, 2003.

30. Dean CB and Nielsen JD: Generalized linear mixed models: A review and some extensions. Lifetime Data Anal 13: 497-512, 2007.

31. Horibe H, Kato K, Oguri M, Yoshida T, Fujimaki T, Kawamiya T, Yokoi K, Watanabe S, Satoh K, Aoyagi Y, et al: Association of a polymorphism of $B T N 2 A 1$ with hypertension in Japanese individuals. Am J Hypertens 24: 924-929, 2011.

32. Arnett HA, Escobar SS and Viney JL: Regulation of costimulation in the era of butyrophilins. Cytokine 46: 370-375, 2009.
33. Oguri M, Kato K, Yoshida T, Fujimaki T, Horibe H, Yokoi K, Watanabe S, Satoh K, Aoyagi Y, Tanaka M, et al: Association of a genetic variant of BTN2Al with metabolic syndrome in East Asian populations. J Med Genet 48: 787-792, 2011.

34. Chae CU, Lee RT, Rifai N and Ridker PM: Blood pressure and inflammation in apparently healthy men. Hypertension 38 399-403, 2001.

35. Schillaci G, Pirro M, Gemelli F, Pasqualini L, Vaudo G, Marchesi S, Siepi D, Bagaglia F and Mannarino E: Increased C-reactive protein concentrations in never-treated hypertension: The role of systolic and pulse pressures. J Hypertens 21: 1841-1846, 2003.

36. Savoia $C$ and Schiffrin EL: Inflammation in hypertension. Curr Opin Nephrol Hypertens 15: 152-158, 2006.

37. Androulakis ES, Tousoulis D, Papageorgiou N, Tsioufis C, Kallikazaros I and Stefanadis C: Essential hypertension: Is there a role for inflammatory mechanisms? Cardiol Rev 17: 216-221, 2009.

38. Law MR, Morris JK and Wald NJ: Use of blood pressure lowering drugs in the prevention of cardiovascular disease: meta-analysis of 147 randomised trials in the context of expectations from prospective epidemiological studies. BMJ 338: b1665, 2009.

39. Stamler J, Rose G, Stamler R, Elliott P, Dyer A and Marmot M: INTERSALT study findings. Public health and medical care implications. Hypertension 14: 570-577, 1989.

40. Ehret GB, O'Connor AA, Weder A, Cooper RS and Chakravarti A: Follow-up of a major linkage peak on chromosome 1 reveals suggestive QTLs associated with essential hypertension: GenNet study. Eur J Hum Genet 17: 1650-1657, 2009.

41. Shriner D, Adeyemo A and Rotimi CN: Joint ancestry and association testing in admixed individuals. PLoS Comput Biol 7: e1002325, 2011.

42. Stoffers DA, Zinkin NT, Stanojevic V, Clarke WL and Habener JF: Pancreatic agenesis attributable to a single nucleotide deletion in the human IPF1 gene coding sequence. Nat Genet 15: 106-110, 1997.

43. Steinthorsdottir V, Thorleifsson G, Sulem P, Helgason H, Grarup N, Sigurdsson A, Helgadottir HT, Johannsdottir H, Magnusson OT, Gudjonsson SA, et al: Identification of lowfrequency and rare sequence variants associated with elevated or reduced risk of type 2 diabetes. Nat Genet 46: 294-298, 2014.

44. Müsch A, Cohen D, Yeaman C, Nelson WJ, Rodriguez-Boulan E and Brennwald PJ: Mammalian homolog of Drosophila tumor suppressor lethal (2) giant larvae interacts with basolateral exocytic machinery in Madin-Darby canine kidney cells. Mol Biol Cell 13: 158-168, 2002.

45. Yasumi M, Sakisaka T, Hoshino T, Kimura T, Sakamoto Y, Yamanaka T, Ohno S and Takai Y: Direct binding of Lgl2 to LGN during mitosis and its requirement for normal cell division. J Biol Chem 280: 6761-6765, 2005. 